\section{Discussion}

This is the first reported case of methotrexateinduced pericarditis and pericardial effusion. The syndrome of methotrexate pleural toxicity is invariably of pleuritic pain with normal chest $\mathrm{X}$-ray and ventilation/perfusion scan. X-Ray changes if present are non-specific and diagnosis may require bronchoscopy and lavage ${ }^{3,7}$ or lung biopsy. ${ }^{7}$ The differential diagnosis is infection, pulmonary infarction and tumourrelated complications. Pleural effusions after methotrexate therapy are most likely to be due to cancer; in this case the fluid should be drained and therapy changed. This patient had methotrexate chemotherapy followed by two episodes of pleurisy, the second being associated with pericarditis and a large pericar-

1 Massin F, Coudert B, Marot JP, Foucher P, Canus P, Jeannin L. Methotrexate pneumonitis. Rev Mal Respir 1990, 7: 5-15

2 Twohig KJ, Matthay RA. Pulmonary effects of cytotoxic agents other than bleomycin. Clin Chest Med 1990; 11: $31-54$.

3 Lehne G, Lote K. Pulmonary toxicity of cytotoxic and immunosuppressive agents; a review. Acta Oncol 1990; 29: 113-24.

4 Biggs JC, Atkinson K, Avalos BR, et al. A multi-institutional study of Bucy 2 followed by allogeneic marrow transplantation in CML. (meeting abstract). Exp Hematol 1991; 19: 572. dial effusion. As in the majority of cases with pleural toxicity there was no peripheral eosinophilia; however, eosinophils were present in the pericardial fluid. An unrecognised viral infection or a reaction to an unsuspected allergen remains a possible cause; however, we believe that the pericardial effusion was most likely a complication of methotrexate chemotherapy and that, as with methotrexate pneumonitis, this is likely to be an immunemediated serositis. ${ }^{7}$ The possibility of pericarditis and significant pericardial effusion should be considered as a potentially severe complication of methotrexate therapy. The regular use of echocardiography could provide information on the incidence of isolated asymptomatic pericardial effusion and that concomitant with methotrexate pneumonitis/pleurisy.

5 Sheridan E, Hancock BW, Smith SC, et al. Gestational trophoblastic disease: experience of the Sheffield (United Kingdom) supraregional screening and treatment service (Review). Int f Oncol 1993; 3: 149-55.

6 Rustin GJS. Trophoblastic diseases. In: Shaw R, et al. Gynaecology. Edinburgh: Churchill Livingstone 1992; pp 562-4.

7 Akoum GM, Maynaud CM, Touboul JL et al. Use of bronchoalveolar lavage in the evaluation of methotrexate lung disease. Thorax 1987; 42: 652-5.

\title{
The association of hereditary neuropathies and heritable skeletal disorders
}

Royal Hallamshire Hospital, Glossop

Road, Sheffield

S10 2JF, UK

Department of

Clinical

Neurophysiology

AK Chattopadhyay

RH Kandler

Department of

Neurology

B Sharrack

Accepted 16 November 1994

\author{
AK Chattopadhyay, RH Kandler, B Sharrack
}

\begin{abstract}
Summary
We describe two patients with associations of hereditary neuropathies and heritable skeletal disorders not previously reported. The first patient had Marfan's syndrome and hereditary motor and sensory neuropathy Type 1 . The second patient had Ehlers-Danlos syndrome, Klippel-Feil syndrome and tomaculous neuropathy.
\end{abstract}

Keywords: hereditary neuropathy, heritable skeletal disorders, Marfan's syndrome, Ehlers-Danlos syndrome, Klippel-Feil syndrome

There are occasional reports of the association between a peripheral neuropathy and Marfan's syndrome, Ehlers-Danlos syndrome, or Klippel-Feil syndrome. ${ }^{1-5} \mathrm{We}$ report two patients with associations not previously described.

\section{Patients}

Case 1

A 19-year-old man presented with progressive difficulty in walking. He had no sensory symptoms. He was of thin build. His paternal grandmother, father and sister were said to have a similar build. On examination, he had bilateral pes cavus and decreased tendon reflexes. He also had arachnodactyly, a high arched palate and bilateral lens dislocations. A diagnosis of Marfan's syndrome and a probable hereditary neuropathy was made.

Echocardiography showed mitral valve prolapse. Nerve conduction studies showed marked slowing of motor conduction velocity in the median nerve $(15 \mathrm{~m} / \mathrm{s}$; lower limit of normal $48 \mathrm{~m} / \mathrm{s}$ ) and absence of sensory action potentials (median, ulnar, radial and sural). Electromyographic examination showed neuropathic changes in tibialis anterior. The findings thus showed a severe demyelinating and degenerating neuropathy consistent with hereditary motor and sensory neuropathy Type I.

Other family members were not available for clinical or electrophysiological examination.

\section{Case 2}

A 16-year-old boy presented with tingling in the distribution of the median nerve in the right hand. He had previously complained of tingling in the little finger of the left hand which was subsiding. On examination, he had blunting to pin prick sensation in the right median 
Table Associations of peripheral neuropathies and heritable skeletal disorders

\begin{tabular}{|c|c|}
\hline Connective tissue or skeletal disorder & Neuropathy \\
\hline Marfanoid features & $\begin{array}{l}\text { Neuropathy ? motor (also UMN signs } \\
\text { and myopathy) }\end{array}$ \\
\hline Marfan's syndrome & Tomaculous neuropathy ${ }^{2}$ \\
\hline Klippel-Feil syndrome & HMSN Type $I^{3}$ \\
\hline Ehlers-Danlos syndrome & Tomaculous neuropathy ${ }^{4}$ \\
\hline Ehlers-Danlos syndrome & Neuropathy (not specified) 5 \\
\hline Marfan's syndrome & HMSN Type $I^{\star}$ \\
\hline $\begin{array}{l}\text { Ehlers-Danlos syndrome and } \\
\text { Klippel-Feil syndrome }\end{array}$ & Tomaculous neuropathy \\
\hline
\end{tabular}

$\mathrm{UMN}=$ upper motor neuron; HMSN = hereditary motor and sensory neuropathy; $\star=$ present report
Case 1 We can find only two reports mentioning the association of either Marfan's syndrome or Marfanoid features and a peripheral neuropathy. ${ }^{1,2}$ A 46-year-old man has been described with Marfanoid features and, amongst other things, proximal muscle weakness, upper and lower motor neuron signs and impaired vibration sense. ${ }^{1}$ An electromyogram showed 'a mild denervation neuropathy with some slowing of conduction'. A muscle biopsy showed a non-specific myopathy. Lack of precise electromyographic findings in the report makes comparison difficult. However, this patient had a combination of myopathic and neuropathic features and there was no suggestion of the neuropathy being hereditary. Our patient had clear evidence of a severe demyelinating and degenerating neuropathy consistent with a hereditary neuropathy.

An association between Marfan's syndrome and tomaculous neuropathy, thought to be fortuitous, has also been described. ${ }^{2}$ However, the report also suggested that ligamentous hyperlaxity in Marfan's syndrome may predispose to pressure palsies. Association with a myopathy has also been reported. ${ }^{6}$

Case 2 Our second patient had EhlersDanlos syndrome, Klippel-Feil syndrome and tomaculous neuropathy. We found two reports of the association between Ehlers-Danlos syndrome and a peripheral neuropathy. ${ }^{4,5}$ In one, the neuropathy was tomaculous in type, ${ }^{4}$ while the other report mentioned the presence of a neuropathy (without characterising it further) in two siblings of consanguineous parents and grandparents. An association between Klippel-Feil syndrome and Charcot-MarieTooth disease has also been described. ${ }^{3}$

Thus there are rare reports, including our own, describing associations between hereditary neuropathies and heritable skeletal disorders. These are summarised in the table.

It is possible that two or more of these disorders have been associated incidentally. On the other hand, these may represent rare manifestations or newer subtypes of recognised genetic syndromes.

We sincerely thank Dr EJW Gumpert and Dr GAB Davies-Jones for allowing us to report their patients.

4 Schady W, Ochoa J. Ehlers-Danlos syndrome in association with tomaculous neuropathy (letter). Neurology 1984; 34 1270 .

Barrison IG, Isenberg DA, Kane SP. Arachnodactyly with unusual neuromyopathic and skeletal abnormalities. $\mathscr{F} R$ Soc Med 1980; 73: 64-8

2 Eymard B, Tome FMS, Brunet P, Fardeau M. Maladie de Marfan et neuropathie tomaculaire familiale. Rev Neurol 1986; 142: 703-5.

3 Viegas CA. Charcot-Marie-Tooth disease associated with Klippel-Feil malformation. Report of a case and review of the literature. Arq Neuropsiquiatr 1980; 38: 193-9.

5 Farag TI, Schimke RN. Ehlers-Danlos syndrome: a new oculo-scoliotic type with associated polyneuropathy? Clin Genet 1989; 35: 121-4.

6 Goebel HH, Muller J, DeMyer W. Myopathy associated with Marfan's syndrome. Neurology 1973; 23: 1257-68. 